\title{
A REVIEW ON THE IMPACT OF INFORMATION CULTURE ON THE ADOPTION OF HEALTH INFORMATION SYSTEM IN DEVELOPING COUNTRIES
}

\author{
${ }^{1}$ Adnan Mukred, ${ }^{1}$ Dalbir Singh and ${ }^{2}$ Nurhizam Safie \\ ${ }^{1}$ School of Computer Science, Faculty of Information Science and Technology, \\ Universiti Kebangsaan Malaysia, Malaysia \\ ${ }^{2}$ International Institute for Global Health, United Nations University, Malaysia
}

Received 2012-08-07, Revised 2013-02-16; Accepted 2013-03-15

\begin{abstract}
The study reviews and attempts to identify the Information Culture factors that impact the users' attitudes toward the adoption of Health Information System (HIS) in developing counties. It is based on a review and a critical analysis of previous research related to the adoption of HIS, especially in developing countries. The study discovered Information Culture related adoption factors: Information Need, Compatibility, Access to Health Information Resources, Information Sharing, Self-efficacy, Attitudes and Awareness towards the importance of HIS. These factors are known to effect the adoption of HIS in developing countries. All these factors suit the context of the current study. Thus, the review outlines the details of each factor and its relevance to the research issue. The outcome of the review-based study revealed that such crucial factors co-exist in two domain areas; Information Culture and HIS adoption.
\end{abstract}

Keywords: Information Culture, Health Information System, HIS Adoption, Developing Countries

\section{INTRODUCTION}

The apparent need for the adoption of Health Information Systems (HISs) and the positive impact that these systems can have on the quality, effectiveness and efficiency of care services have been analyzed and depicted over the years in the health informatics literature studies. In many European nations, as well as other countries around the world, there is a growing awareness that strategic investments in innovative clinical information system as well as other types of (HISs) can yield significant improvement for an entire healthcare system (Kitsiou et al., 2010). In developing countries, it is important to adopt a holistic approach to cultivate a more mature Information Culture in healthcare system to increase the adoption level of the technological innovation. This means that to adopt such a holistic approach, it is necessary to build conditions and capacities for interpreting, evaluating and utilizing information resources (Zheng, 2005).
Information culture is currently becoming one of the important criteria of general personality culture. The information culture level of a contemporary man/woman is determined by many factors such as his/her realisation of the information needs, the knowledge available in both traditional and electronic sources, the ability to use such sources, to seek and find them, the possession of elementary information analysis skills. Information culture development is the process in the context of which different knowledge, abilities and skills are created to allow the information consumer to find ways in the information space (Shemberko, 2005).

A key issue concerns the strengthening of the information culture, which is argued to be best approached through taking elements of the existing of "old" and blending it with aspects of the "new" primarily relating to the computerization efforts of the HISP initiative. Thus, this strengthening leads to improving the quality of the routine health reports and developing the capacity of the

Corresponding Author: Adnan Mukred, School of Computer Science, Faculty of Information Science and Technology,

Universiti Kebangsaan Malaysia, Malaysia 
health staff to use the information technology to support their local and everyday activities (Mosse, 2004).

Curry and Moore (2003) considered Information Culture as a culture in which the value and utility of information in achieving operational and strategic success is recognized, where ICT is readily exploited as an enabler for effective information systems. Moreover, Martin et al. (2003) defined Information Culture as a system of shared meanings and knowledge that are enacted through people, processes and technology. Braa et al. (2004) argued that the organizational and environmental determinants are related to the Information Culture within the context of a given country. Therefore, the organizations which are able to both share information freely and develop cultures of information perform at much higher levels than those that are unable to share information or develop cultures of information. To further this, the development of a locally driven Information Culture is the key to sustainable development (Williamson et al., 2001). Cultivation of an Information Culture in an enterprise can create an atmosphere that enables safety professionals to realize the importance of knowledge about and appropriate attitudes towards using ICT in information processing (Yang, 2012).

Looking at Information Culture from the perspective of developmental outcomes, one can argue that there are better ways of using information resources than what is currently the case in many parts of the world. This implies that what has been investigated in Information Culture in a certain context of the world may not be applicable to investigating the same area in another context of the world. As previously argued by (Braa et al., 2004) that investigating Information Culture in a given country is determined by the environmental and the organizational factors within the context of a given country. Moreover, it was argued by Braa et al. (2004) that analyzing the data at facility level in a given country is an important aspect of creating a "culture of information use, which means that it is important to analyze the data at the local level in a given country.

As for the study area investigated in the current study, in general, the information has not been regarded as a culture in developing countries especially in HIS. Therefore, the current paper aims to investigate the extent to which Information Culture factors affect the HIS in such countries.

\subsection{Review of Previous Studies: Information Culture}

A detailed review of the previous literature on Information Culture and the adoption of HIS in healthcare sectors in different contexts is presented.
Based on the literature review, there is no consensus yet on the meaning of the term 'Information Culture' and one can find different insights from different authors. Therefore, there is a need for a deeper, more synthesised and theorised conceptualisation. Davenport and Prusak (1997) defined Information Culture in terms of "a pattern of behaviors and attitudes that express an organization's orientation toward information". Social attitudes have changed with the effect that citizens of a society now expect the various elements of that society to be better informed than it was previously. An example of information cultural attitudes is preferences for facts or rumors and examples of information cultural behavior include information sharing and preferences for types of communication channel such as face-to-face vs. email. In a similar definition, Travica (2005) has defined Information Culture in terms of stable beliefs and behaviors. Beliefs are defined as "values, norms and attitudes" and behavior as "work practices and communication" that refer to organizational information and ICT. In addition, beliefs have been proved to influence attitude towards behavior (Croll, 2009). Work practices refer to accustomed ways of working and communication behaviors imply communication content, channels and language. These two previous definitions of Information Culture have been perceived as the most popular definitions in the literature. Information Culture incorporates have been defined as the general capability, views, norms and rules of behaviour, with regard to accessing, understanding and using information (Zheng, 2005).

As argued by Travica (2005), Information Culture is a part of the organizational culture that revolves around information and ICT, which both (the culture of the organization and Information Culture) have mutual influence. Moreover, Choo et al. (2008) regarded Information Culture as those elements of an organization's culture that influence its management and use of information. Thus, Information Culture is manifested in the organization's values, norms and practices that have an impact on how information is perceived, created and used. Values are the deeply held beliefs about the role and contribution of information to the organization as well as the principles that define how information ought to be created and used. Norms are rules or socially accepted standards that define what information behaviors are normal or to be expected in the organization. Riyaz (2009) argued that the concept of Information Culture is relevant to the ways in which people value, use, approach and handle information. Information Culture has also been considered as one of the six elements of an information infrastructure model by (Granger, 1999). Moreover, Davenport and Prusak (1997) 
distinguished between Information Culture pertaining to the group and organizational level and information behaviours that are demonstrated at the individual level (e.g., searching for information and using it).

Zheng (2005) identified the capability of accessing, interpreting and using information to form valid opinions based on the results as part of Information Culture.

In a more detailed discussion of Information Culture advocated by Zheng (2005), seven ways in which individuals experience Information Culture were identified. They are ICT (using information technology for information awareness and communication), information sources (finding information from appropriate sources), executing process (experience of problem solving or decision-making), information control (focussing on bringing relevant information within their personal sphere), knowledge construction, knowledge extension and even wisdom. Information Culture approaches are aimed at the development of a person's ability to receive, evaluate and use information given in any form or by various technologies. Knowledge sharing and attitudes toward shared knowledge are also key elements for investigating Information Culture (Curry and Moore, 2003). Shemberko (2005) has defined a person from this perspective as one who recognizes the need for information; recognizes that accurate and complete information is the basis for intelligent decision-making, identifies the potential sources of information, develops successful search strategies, accesses sources of information including computer-based and other technologies, evaluates information, organizes information for practical application, integrates new information into an existing body of knowledge and uses information for problem solving. In order for information technology and knowledge to be appreciated and integrated into less fortunate societies, the majority of people need access to computers and the Internet.

Previous studies have also linked between Information Culture and information behaviour. Information behaviors and values, norms and attitudes that underpin those behaviors- could provide evidence of an Information Culture (Choo et al., 2006). While some researchers use "information behaviour" to refer only to information-seeking activities in a behavioural sense, others such as Wilson (1997), use it more broadly to describe those activities a person may engage in when identifying his or her own needs for information, searching for such information in any way and using or transferring that information. Wilson (1997) also rephrased the behaviour as the totality of human behaviour in relation to sources and channels of information. Knowledge and information behaviours are indicated by "how individuals approach and handle information (Davenport and Prusak, 1997). These behaviours include creating and/or seeking information, information sharing or hoarding, responding to inquiries, making contributions to knowledge repositories and utilizing or ignoring information (Davenport and Prusak, 1997; Choo et al., 2008).

\subsection{Review of Information Culture in Health System}

The importance of developing an appropriate Information Culture has been recognized in the area of health systems. According to (Simwanza and Church, 2001), the term of Information Culture was used to refer to a culture of constant use of data around the health management information system in Zambia. The report of the Posner (2002) has stressed the significance of shaping a 'culture of information' and particularly, in relation to the attitude and experience of health users in using information to facilitate decision making and actions. For example, in South Africa, it is put on the agenda to create a culture of information use at all levels. According to Williamson et al. (2001), using Information for planning and daily management of health services is often referred to as the existence of a local 'Information Culture'.

Developing countries have often been challenged to improve their healthcare through the use of ICT in order to upgrade the health status of their people. (Kimaro and Twaakyondo, 2005) pointed out that despite tremendous local and international efforts and resources made and spent during the last decade on the healthcare development and implementation, the system is still unreliable due to many factors including a lack of culture of information and ICT use, appropriate human capacity, infrastructure and administrative commitment. Zheng (2005) concluded that developing countries need to take truly steps into the information society for adopting holistic approaches that are sensitized towards cultivating a modern Information Culture and make incremental social institutional changes alongside technological innovations.

\subsection{Review of Barriers and Challenges Faced by Information Culture}

This sub-section provides a review of previous studies investigating and identifying various factors and 
challenges working against Information Culture in different contexts of the world. Granger (1999) identified four forces which work against developing and sustaining an Information Culture. These include the misuse of information, the general lack of spatial awareness shown by many decision makers, the widespread fear of information and knowledge and the general lack of good information management practices. Moreover, lack of broad understanding in society of the importance of the Information Culture of an individual, lack of formed opinion about the danger of non-using the information and an inability to work with information were as barriers faced by Information Culture (Zheng, 2005). Furthermore, Leidner and Kayworth (2006) stressed the importance of understanding a culture in information technologies in that the culture at various levels including national, organizational and group can influence the successful implementation and use of information technology. Health services need to focus on growing an Information Culture underpinned by a performance management framework that is meaningful to clinicians and managers and supports them in their daily work (Hanson, 2011).

Organizational and environmental determinants are related to the Information Culture within the context of a given country. In supporting this opinion, in Africa, the new Information Culture is a hybrid of the new and the old. Therefore, the adoption of the Anglo-American model imposed on the African libraries was inefficient as reported by (Plessis, 2008). Plessis (2008), added that the Information Culture in Anglo-American societies differ from that in Africa. Travica (2005) studied the influence of Information Culture on the adoption of a self-service system and he argued that a tendency toward criticizing new things refers to one of the derived information cultural aspects. He (cite author, year) pointed out that people in their company like to criticize and complain a lot. Criticizing is the first reaction to almost anything new that occurs in the corporate life. This is especially when the new thing is an Information System as this custom drives attention to downsides of a new system, while pushing potential benefits out of the attention span. Therefore, the adoption of the Information Culture requires senior management support with an emphasis on coordinated leadership rather than merely imposition from the top to down bearing in mind the close links between the organizational culture and Information Culture (Curry and Moore, 2003). In summing up the concept of Information Culture, it is defined as stable attitudes and behaviors that recognize the compatibility and the need for information construction through building users' awareness, capacity and information sharing. Table 1 summarizes Information Culture factors and dimensions from previous literature review

\subsection{Review of Previous Literature on the Adoption of HIS}

Recently, HISs in developing countries have gained more and more attention as more efforts made by governments, international agencies, nongovernmental organizations, donors and other development partners seek to improve healthcare (Nyella, 2009). National Culture, in the sense of the shared traditions and representations of a society, has a profound effect on the design, adoption and the use of Information Technologies in each society (Moghadam and Assar, 2008). At the beginning, computer-supported health information systems were primarily intended to support health care professionals, mainly physicians, as well as administrative staff in hospitals. Later, there was also a focus on nurses. For the last few years, the focus has shifted to support patients and their relatives often denoted as health consumers (Reinhold, 2006). HIS is defined as a system that integrates data collection, processing, reporting and use of the information necessary for improving health service effectiveness and efficiency through better management at all levels of health services (Reichertz, 2006). HIS range from simple systems such as transaction processing systems to complex systems such as Clinical Decision Support Systems (CDSS) (Yusof et al., 2006). Thus, the adoption of health information systems is seen world wide as one method to mitigate the widening health care demand and supply gap (Ludwick and Doucette, 2009).

In the healthcare sector, how Information Systems (IS) is adopted may be critical when the IS relates to human lives (Hu et al., 2000). Such adoption is also affected by multiple actors that have different backgrounds and interests (Wiley-Paton and Malloy, 2004). Healthcare actors often resist the adoption of IS and it has, therefore, been suggested that they should carefully manage as their role is important during the adoption process (Chen, 2003). Thus, the Heidelberg HIS working group's conference of the International Medical Informatics Association (IMIA) in 2003 stated that "people, not technology, will ultimately determine the success of HIS. Kijsanayotin et al. (2009) stated that the knowledge of how people who 
work in the healthcare sector accept and use health ICT, their basic ICT knowledge and factors that influence their ICT acceptance and use not only help health information system designers but also enable more efficient implementation and evaluation processes. Moreover Yusof et al. (2006) pointed out that provision of health care is increasingly shaped by the adoption of HIS which is a group of processes implemented to aid in enhancing the efficiency and effectiveness of healthcare organization in performing its functions and attaining its objectives.

Littlejohns et al. (2003) reported the reasons for failure of a large computerized HIS project in developing countries like South Africa resulted from a lack of users' understanding of reasons for the new system and the underestimation of the complexity of the healthcare system. The lack of acceptance is a fundamental barrier to the implementation of HISs (Croll, 2009). The same researcher argued that there are many reasons for the lack of acceptance or actual resistance to HISs, such as unwillingness of stakeholders to learn new routines, lack of ICT training as major barriers to the acceptance and implementation of HISs and lack of insight into the benefits and lack of concern about the sheer magnitude of the change caused by HIS (Croll, 2009). Young (1984) identified the nature of the doctor's work, his attitudes, interests and enthusiasms to be the major reasons for the non-acceptance of computer systems.

Table 1. Information Culture factors

Author/ Year Information Culture dimensions/factors

(Widen-Wulff, 2000)

(Curry and Moore, 2003)

(Granger, 1999)

(Martin et al., 2003)

(Yang, 2012)

(Zheng, 2005)

(Choo et al., 2008)

(Oliver, 2008)

(Webber and Johnston, 2000)

(Travica, 2005)

(Katopol, 2007)

(Ponjuan, 2002)

(Collins, 2010)

(Riyaz, 2009)
(1) Information flow (2) Information communication (3) Knowledge creation

(4) Information channels (5), IT and (6) Attitudes

(1) Communication flows (2) Cross-organizational partnerships (3) Internal environment

(4) Information systems management (5) Information management (6) Processes and procedures,

(1) Information management (2) Information awareness (3) Information use (4)

Widespread fear.

(1) Shared understanding of or generational direction (2) Common language (3)

Terminology to enable dialogue

(1) Individual and group values, (2) Attitudes, (3) Perceptions, (4) Competencies and (5) Patterns of behavior

(1) Information literacy, (2) Information openness and (3) Information norms

(1) Information integrity, (2) Formality, (3) Control, (4) Sharing, (4) Transparency and (5) Proactivenes

(1) Recognition and acceptance of societal and organizational requirements,

(2) Attitudes to sharing information,

(3) Utilizations of information technology, (4) Preference for low or high context communication and

(5) Trust in written documentation.

(1) Recognizes the need for information; (2) Recognizes that accurate and complete information

(3) Identifies potential sources of information; (4) Develops successful search strategies;

(5) Accesses sources of information (6) Evaluates information; (7) Organizes information

(8) Integrates new information into an existing body of knowledge; and

(9) Uses information in critical thinking and problem solving.

(1) Communication channel, (2) Information sharing practices, (3) Background knowledge,

(4) Accomplishing performance goals and (4) Match between technological infrastructure and process efficiency needs.

(1) Information retrieval, (2) Information creation, (3) Information storage,

(4) Information transfer,

(5) Information exchange and (6) Information dissemination

(1) Human, (2) Information (information needs, generation and dissemination),

(3) Infrastructure ,

(4) Cooperation, (5) Leadership and (6) Social conditions

(1) Information behavior of knowledge sharing, (2) Attitudes toward sharing and

(3) Attitudes toward shared knowledge.

(1) Indigenous knowledge, (2) Information literacy, (3) Research - development and publishing

(4) Mass media and (5) Information policies 
Thus, Agrawal (2011) argued that some studies suggest that physicians may be more reticent to adopt PHRs than other health professionals. This reticence is mainly due to the concerns about whether adoption of PHRs will create additional work that is not reimbursed. Therefore, the adoption of HISs in primary care is hampered by clinicians' concerns that privacy, patient safety, quality of care and efficiency will decline after the implementation (Ludwick and Doucette, 2009). Ludwick and Doucette (2009) added that physicians do not adopt electronic health information systems due to high costs, risks of liability and data security. ICT adoption in a clinical environment depends on the fit between the attributes of the individual users, attributes of the technology and attributes of the clinical tasks and processes (Melas et al., 2011).

The main findings by Yusof et al. (2008) showed that having the right user attitude and skills base together with good leadership, ICT-friendly environment and good communication have positive influence on the system adoption. In addition, Mosse (2004) stated that HISs emphasize aspects of humans, technologies, organizational procedures and their inter-linkages. Individual, organizational, technological and external environmental factors were identified as factors that impede or facilitate e-health adoption (Baroud, 2008).

Croll (2009) identified some barriers facing HISs, which include factors such as system failure, cost, fears about confidentiality, security and privacy, inefficiency, poorer quality of healthcare, the change in the work process, complexity of healthcare and lack of acceptance by clinicians. Croll (2009) added that usability is important to the adoption of health information systems. Lack of awareness, information sharing and accessing information are among the barriers to acceptance of ICT. Kushniruk and Borycki (2008) argued that lack of ease of use of HISs has been a major impediment to the adoption of such systems. Usability is a major factor for the successful adoption of any EHRs systems as one type of HISs (Zhang, 2005). Yusof et al. (2008) identified accessibility as one of the dominant factors of HIS adoption. Rahimi (2008) identified other factors that influence the success of HIS implementation such as management involvement, integration with healthcare workflow, establishing compatibility between software and hardware and most importantly, user involvement, education and training may accelerate HIS adoption. Rahimi (2008) also argued that while the research literature clearly documents an increasing number of benefits of Health Information Technology (HIT), it also identified a number of barriers to the widespread adoption of these systems: physician acceptance, security, authentication concerns and improper primary focus on technology. Yusof et al. (2008) identified adoption factors of HISs of the specific users in the particular setting such as digital Fundus Imaging System (FIS); factors that had influenced the adoption negatively include: system usefulness, response time, technical support, empathy of service quality, user perception and user skills. Meanwhile, factors contributing to the positive adoption of FIS include information relevancy, user attitude, leadership, medical sponsorship, organizational readiness, clinical process and external communication with the inter-organizational system. Callen et al. (2008) stated that the relationship between culture and attitudes towards clinical information systems should be taken into account when planning for their adoption in healthcare. Widespread adoption and use of PHRs may not occur unless (1) the technology provides perceptible value to users (usefulness) and is easy to learn and use and (2) more general education is given on the uses of health information to increase health literacy (Hart, 2003).

However, it is believed by Meredith (2002) that the real benefits of advanced ICT have until now been gained only by the developed world and are accessible only to some in the developing world. As stated by a study cited in Kijsanayotin et al. (2009), it was argued that more than $40 \%$ of ICT developments in various sectors including the health sector have failed or been abandoned and one of the major factors leading to the failure is the inadequate understanding of the sociotechnical aspects of ICT, particularly the understanding of how people and organizations adopt ICT. Moreover, the knowledge of how people who work in the health sector accept and use health ICT, their basic ICT knowledge and factors that influence their ICT acceptance and use will enable more efficient implementation and evaluation processes. Kijsanayotin et al. (2009) showed that Intention to use health ICT is a function of various concepts including the perception that health ICT is useful, not too difficult to use, important persons/others believed that he/she should use health ICT and the perception of free will to use ICT influence the intention to use. Maria (2011) identified and categorised barriers to HIT adoption under five headings namely; structure of healthcare organisations, tasks, people policies, incentives and information and decision processes. Yusof et al. (2008) argued that the majority of existing studies on IHSs tends to focus on technical issues or clinical processes. However, such aspects do not provide an explanation of the reasons of the effective or poor function of these systems in relation to a specific user in a specific setting. Table 2 shows adoption factors from previous studies. 
Table 2. HIS adoption factors

\begin{tabular}{|c|c|}
\hline Author/ Year & Adoption factors \\
\hline (Hart, 2003) & $\begin{array}{l}\text { (1) Perceived usefulness, (2) Technology self-efficacy, (3) Perceived ease-of -use, } \\
\text { (4) Perceived behavioral control, (5) Health literacy and (6) Health Status. }\end{array}$ \\
\hline (Callen et al., 2008) & (1) Organizational context, (2) Clinical unit context and (3) Individual context \\
\hline (Yu et al., 2009) & $\begin{array}{l}\text { (1) Perceived usefulness, (2) Perceived ease of use, (3) Social influences, } \\
\text { (4) Demographic variables (age, job level, work experience, computer skills) }\end{array}$ \\
\hline (Nwabueze et al., 2009) & $\begin{array}{l}\text { (1) Voluntariness, (2) Age, (3) Gender, (4) Experience, (5) Performance expectancy, } \\
\text { (6) Effort expectancy, (7) Facilitating conditions, (8) Social influence, } \\
\text { (9) Behaviors intention, (10) Usage behavior and (11) Access }\end{array}$ \\
\hline (Ludwick and Doucette, 2009) & $\begin{array}{l}\text { (1) Privacy, (2) Patient safety, (3) Quality of care, (4) Efficiency, } \\
\text { (5) Risks of liability and (6) Data security. }\end{array}$ \\
\hline (Or and Karsh, 2009) & $\begin{array}{l}\text { (1) Patient (age, gender), (2) Human-technology interaction ( perceived usefulness } \\
\text { and perceived ease of use), }\end{array}$ \\
\hline & (3) Organization and environment and (4) Task (compatibility) \\
\hline (Pai and Huang, 2011) & $\begin{array}{l}\text { (1) Information quality, (2) Service quality, (3) System quality, (4) Perceived usefulness, } \\
\text { (5) Perceived ease of use and (6) Intention to use }\end{array}$ \\
\hline (Kijsanayotin et al., 2009) & $\begin{array}{l}\text { (1) Performance expectancy, (2) Effort expectancy, (3) Social influence, (4) Intention to use, } \\
\text { (5) Voluntariness, (6) IT knowledge, (7) Experience and (8) IT use }\end{array}$ \\
\hline (Maria, 2011) & $\begin{array}{l}\text { (1) Structure of healthcare organizations; (2) Tasks; (3) People policies; (4) Incentives; and } \\
\text { (5) Information and decision processes }\end{array}$ \\
\hline (Rahimi, 2008) & $\begin{array}{l}\text { (1) Management involvement, (2) Integration with healthcare workflow, } \\
\text { (3) Establishing compatibility between software and hardware and (4) User involvement }\end{array}$ \\
\hline (Melas et al., 2011) & $\begin{array}{l}\text { (1) ICT knowledge and ICT feature demands, (2) Physician specialty, } \\
\text { (3) Perceived usefulness, }\end{array}$ \\
\hline (Schaper and Pervan, 2007) & $\begin{array}{l}\text { (4) Perceived ease of use, (5) Attitudes toward use and (6) Behavioral Intention to use } \\
\text { (1) Performance expectancy, (2) Effort expectancy, (3) Subjective norm, } \\
\text { (4) Facilitating conditions, (5) Social influence, (6) Behaviors intention, (7) Usage behavior, } \\
\text { (8) Computer attitude, (9) Computer anxiety, (10) Computer self efficacy, } \\
\text { (11) Training and (12) Compatibility, }\end{array}$ \\
\hline $\begin{array}{l}\text { (Aggelidis and Chatzoglou, } \\
\text { 2009) }\end{array}$ & $\begin{array}{l}\text { (1) Perceived usefulness, (2) Ease of use, (3) Social influence, (4) Attitude, } \\
\text { (5) Facilitating conditions and (6) Self-efficacy }\end{array}$ \\
\hline (Tian, 2012) & $\begin{array}{l}\text { (1) Relative advantage, (2) Compatibility; (3) Complexity, (4) Trialability and } \\
\text { (5) Observability }\end{array}$ \\
\hline (Yusof et al., 2008) & $\begin{array}{l}\text { (1) System usefulness, (2) Response time, (3) Technical support, } \\
\text { (4) Empathy of service quality, }\end{array}$ \\
\hline & $\begin{array}{l}\text { (5) User perception and user skills, (6) Information relevancy, (7) User attitude, } \\
\text { (8) Leadership, (9) Medical sponsorship, (10) Organizational readiness, }\end{array}$ \\
\hline (Young, 1984) & $\begin{array}{l}\text { (11) Clinical process and (12) External communication with the inter-organizational system } \\
\text { (1) Nature of the doctor's work, (2) Attitudes, (3) Interests and (4) Enthusiasms }\end{array}$ \\
\hline (Zhivan and Diana, 2012) & (1) Hospital characteristics(hospital cost inefficiency) and 2- environmental factors \\
\hline (Venkatesh et al., 2011) & $\begin{array}{l}\text { (1) Voluntariness, (2) Age, (3) Gender, (4) Experience, (5) Performance expectancy, } \\
\text { (6) Effort expectancy, (7) Facilitating conditions, (8) Social influence, } \\
\text { (9) Behaviors intention and } \\
\text { (10) Usage behavior }\end{array}$ \\
\hline (Reginatto, 2012) & (1) ICT skills, (2) Contact, (3) Confidentialityand (4) Familiarity \\
\hline (Ifinedo, 2012) & $\begin{array}{l}\text { (1) Performance expectancy, (2) Effort expectancy, (3) Facilitating conditions, } \\
\text { (4) Social influence, } \\
\text { (5) Behaviors intention , (6) Usage behavior, (7) Compatibility }\end{array}$ \\
\hline
\end{tabular}

From the previously stated definitions and the components of Information Culture and the factors having impact on HIS adoption, the current study investigated the extent to which Information Culture factors impact the adoption of HISs in developing countries.
Thus, studying the Information Culture factors surrounding the adoption of HIS is appropriate for several reasons. The concept of Information Culture has been shown to have a fairly large affect on information behaviour and individual attitudes, but, as 
yet, has not been studied in depth (Choo et al., 2006; 2008). The information is not yet considered as a culture in developing countries and therefore, the potential of using computers in Health centers is not adequately utilized because the attitude of staff towards the use of HIS is not clear and the internal and external communication and information exchange is not fully institutionalized.

\section{CONCLUSION}

The aim of the study was to investigate the impact of Information Culture factors for HISs in developing countries. Based on the literature review of previous studies, the present study identified six (6) factors as its primary contribution: (1) Perceived need, (2) Compatibility, (3) Access to health information resources, (4) Self-efficacy, (5) information sharing and (6) Awareness towards the importance of HIS as important factors which impact the users' attitude towards the adoption of HIS in developing countries. These factors are the common shared factors investigated in studies related to Information Culture and HIS adoption in developing countries. Besides that, such study opens further opportunities for the formulation of framework that outlines the Information Culture factors and adoption of HIS in developing countries.

\section{REFERENCES}

Aggelidis, V.P. and P.D. Chatzoglou, 2009. Using a modified technology acceptance model in hospitals. Int. J. Med. Inform., 78: 115-126. DOI: 10.1016/j.ijmedinf.2008.06.006

Agrawal, A.A., 2011. Current trends in the evolutionary ecology of plant defence. Funct. Ecol., 25: 420-432. DOI: $10.1111 / \mathrm{j} .1365-2435.2010 .01796 . x$

Baroud, R.M., 2008. How ready are the stakeholders in the Palestinian healthcare system in the Gaza Strip to adopt e-Health? Ist Edn., Library and Archives, Ottawa, ISBN-10: 0494380101, pp: 254.

Braa, J., O.H. Titlestad and J. Saebo, 2004. Participatory health information systems development in Cuba: The challenge of addressing multiple levels in a centralized setting. Proceedings of the 8th Conference on Participatory Design: Artful integration: Interweaving Media, Materials and Practices, (MMP' 04), ACM Press, New York, USA., pp: 53-64. DOI: 10.1145/1011870.1011877
Callen, J.L., J. Braithwaite and J.I. Westbrook, 2008. Contextual implementation model: A framework for assisting clinical information system implementations. J. Am. Med. Inform. Assoc., 15: 255-262. DOI: 10.1197/jamia.M2468

Chen, M., 2003. Factors affecting the adoption and diffusion of XML and web services standards for E-business systems. Int. J. Hum. Comput. Stud., 58: 259-279. DOI: $10.1016 / \mathrm{s} 1071-$ 5819(02)00140-4

Choo, C.W., C. Furness, S. Paquette, H.V.D. Berg and B. Detlor et al., 2006. Working with information: Information management and culture in a professional services organization. J. Inform. Sci., 32: 491-510. DOI: 10.1177/0165551506068159

Choo, C.W., P. Bergeron, B. Detlor and L. Heaton, 2008. Information culture and information use: An exploratory study of three organizations. J. Am. Soc. Inform. Sci. Technol., 59: 792-804. DOI: 10.1002/asi.20797

Collins, C.D., 2010. Knowledge and information sharing: A multiple-case study of the information culture of the British Columbia salmon fishery. Indiana Uninersity.

Croll, J., 2009. The impact of usability on clinician acceptance of a health information system. Ph.D. Thesis, Queensland University of Technology.

Curry, A. and C. Moore, 2003. Assessing information culture-an exploratory model. Int. J. Inform. Manage., 23: 91-110. DOI: 10.1016/s02684012(02)00102-0

Davenport, T.H. and L. Prusak, 1997. Information Ecology: Mastering the Information and Knowledge Environment. 1st Edn., Oxford University Press, ISBN-10: 0195111680, pp: 272.

Granger, K., 1999. An Information Infrastructure for Disaster Management in Pacific Island Countries. 1st Edn., Australian Geological Survey Organisation, Canberra, ISBN-10: 0642397961, pp: 71.

Hanson, R.M., 2011. Good health information-an asset not a burden. Australian Health Rev., 35: 9-13. DOI: 10.1071/AH09865

Hart, T.A., 2003. Acceptance and adoption of health information technology: An assessment of attitudes toward personal health records. MSc Thesis, Wichita State University. 
Hu, P.J.H., P.Y.K. Chau and O.R.L. Sheng, 2000. Investigation of factors affecting healthcare organization's adoption of telemedicine technology. Proceedings of the 33rd Annual Hawaii International Conference on System Sciences, Jan. 4-7, IEEE Xplore Press, pp: 10-10. DOI: 10.1109/hicss.2000.926799

Ifinedo, P., 2012. Technology acceptance by health professionals in Canada: An analysis with a modified UTAUT model. Proceedings of the 45th Hawaii International Conference on System Science, Jan. 4-7, IEEE Xplore Press, Maui, HI., pp: $2937-$ 2946. DOI: 10.1109/hicss.2012.556

Katopol, P.F., 2007. Information culture of support staff in municipal government and implications for managerial decision-making. Udini.

Kijsanayotin, B., S. Pannarunothai and S.M. Speedie, 2009. Factors influencing health information technology adoption in Thailand's community health centers: Applying the UTAUT model. Int. J. Med. Inform., 78: 404-416. DOI: 10.1016/j.ijmedinf.2008.12.005

Kimaro, H.C. and H.M. Twaakyondo, 2005. Analysing the hindrance to the use of information and technology for improving efficiency of health care delivery system in Tanzania. Tanzania J. Health Res. Bull., 7: 189-197. PMID: 16941947

Kitsiou, S., V. Manthou, M. Vlachopoulou and A. Markos, 2010. Adoption and sophistication of clinical information systems in Greek public hospitals: Results from a national web-based survey. Proceedings of the 12th Mediterranean Conference on Medical and Biological Engineering and Computing, May 27-30, Springer Berlin Heidelberg, Chalkidiki, Greece, pp: 1011-1016. DOI: 10.1007/978-3-642-13039-7_256

Kushniruk, A.W. and E.M. Borycki, 2008. Human, social and organizational aspects of health information systems. 1st Edn., IGI Global Snippet, Hershey, ISBN-10: 1599047942, pp: 300.

Leidner, D.E. and T. Kayworth, 2006. Review: A review of culture in information systems research: Toward a theory of information technology culture conflict. MIS Q., 30: 357-399.

Littlejohns, P., J.C. Wyatt and L. Garvican, 2003. Evaluating computerised health information systems: Hard lessons still to be learnt. Br. Med. J., 326: 7394-860. DOI: 10.1136/bmj.326.7394.860
Ludwick, D.A. and J. Doucette, 2009. Adopting electronic medical records in primary care: Lessons learned from health information systems implementation experience in seven countries. Int. J. Med. Inform., 78: 22-31. DOI: 10.1016/j.ijmedinf.2008.06.005

Maria, L., 2011. Healthcare professionals' organisational barriers to health information technologies-A literature review. Int. J. Med. Inform., 80: 849-862. DOI: 10.1016/j.ijmedinf.2011.09.005

Martin, V.A., M. Lycett and R. Macredie, 2003. Exploring the gap between Business and IT: An information culture approach. Brunel University.

Melas, C.D., L.A. Zampetakis, A. Dimopoulou and V. Moustakis, 2011. Modeling the acceptance of clinical information systems among hospital medical staff: An extended TAM model. J. Biomed. Inform., 44: 553-564. DOI: 10.1016/j.jbi.2011.01.009

Meredith, E., 2002. Public Sector Governance-Future Issues for Australia. Australian J. Public Admin., 61: 51-61. DOI: 10.1111/1467-8500.00272

Moghadam, A.H. and P. Assar, 2008. The relationship between national culture and e-adoption: A case study of Iran. Am. J. Applied Sci., 5: 369-377. DOI: 10.3844/ajassp.2008.369.377

Mosse, E.L., 2004. Understanding the introduction of computer-based Health Information Systems in developing countries: Counter Networks, communication practices and social identity a case study from Mozambique. University of Oslo Norway.

Nwabueze, S.N., P.N. Meso, V.W. Mbarika, M. Kifle and C. Okoli et al., 2009. The effects of culture of adoption of telemedicine in medically underserved communities. Proceedings of the 42nd Hawaii International Conference on System Sciences, Jan. 5-8, IEEE Xplore Press, Big Island, HI., pp: 1-10. DOI: $10.1109 /$ hicss.2009.430

Nyella, E., 2009. Challenges in health information systems integration: Zanzibar experience. Proceedings of the International Conference on Information and Communication Technologies and Development, Apr. 17-19, IEEE Xplore Press, Doha, pp: 243-251. DOI: 10.1109/ictd.2009.5426679 
Oliver, G., 2008. Information culture: Exploration of differing values and attitudes to information in organisations. J. Document., 64: 363-385. DOI: 10.1108/00220410810867588

Or, C.K.L. and B.T. Karsh, 2009. A systematic review of patient acceptance of consumer health information technology. J. Am. Med. Inform. Assoc., 16: 550560. DOI: 10.1197/jamia.M2888

Pai, F.Y. and K.I. Huang, 2011. Applying the Technology Acceptance Model to the introduction of healthcare information systems. Technol. Forecast. Soc. Change, 78: 650-660. DOI: 10.1016/j.techfore.2010.11.007

Plessis, J.C.D., 2008. From food silos to community kitchens-Retooling African libraries. Int. Inform. Library Rev., 40: 43-51. DOI: 10.1016/j.iilr.2007.09.001

Ponjuan, G., 2002. Role of collaboration among leaders from various sectors in creating an information culture. Department of Library and Information Science.

Posner, S., 2002. Developing a culture of information as a key determinant of sustainable quality information availability and use. Health Reform Plus Project.

Rahimi, B., 2008. Implementation of Health Information Systemsh [Elektronisk resurs]. 1st Edn., Linkoping University Electronic Press, Linkoping, pp: 17.

Reginatto, B., 2012. Addressing barriers to wider adoption of telehealth in the homes of older people: An exploratory study in the irish context. Proceedings of the 4th International Conference one Health, Telemedicine and Social Medicine, Jan. 30Feb. 4, IARIA, Valencia, Spain, pp: 175-183.

Reichertz, P.L., 2006. Hospital information systemsPast, present, future. Int. J. Med. Inform., 75: 282299. DOI: 10.1016/j.ijmedinf.2005.10.001

Reinhold, H., 2006. Health information systems-past, present, future. Int. J. Med. Inform., 75: 268-281. DOI: 10.1016/j.ijmedinf.2005.08.002

Riyaz, A., 2009. The information culture of the Maldives: an exploratory study of information provision and access in a small island developing state. Curtin University of Technology.

Schaper, L.K. and G.P. Pervan, 2007. ICT and OTs: A model of information and communication technology acceptance and utilisation by occupational therapists. Int. J. Med. Inform., 76: S212-S221. DOI: 10.1016/j.ijmedinf.2006.05.028
Shemberko, L., 2005. Information Culture of Digital Information Users (Case Study: Social and Humanitarian Sciences). Institute of Scientific Information in Social Sciences.

Simwanza, A. and M. Church, 2001. Establishment of an information culture: Achievements and Challenges in Zambia achievements and challenges in Zambia. Proceedings of the workshop on Issues and Innovation in Routine Health Information in Developing Countries, Mar. 14-16, Potomac, MD.

Tian, X., 2012. Factors Influencing Decision-Making of Acute Care Hospitals on Adopting Complementary and Alternative Medicine. 1st Edn., BiblioBazaar, ISBN-10: 1249042143, pp: 152.

Travica, B., 2005. Information politics and information culture: A case study. Inform. Sci. J., 8: 211-244.

Venkatesh, V., T.A. Sykes and X. Zhang, 2011. 'Just what the doctor ordered': A revised UTAUT for EMR system adoption and use by doctors. Proceedings of the 44th Hawaii International Conference on System Sciences, Jsn. 4-7, IEEE Xplore Press, Kauai, HI., pp: 1-10. DOI: 10.1109/HICSS.2011.1

Webber, S. and B. Johnston, 2000. Conceptions of information literacy: New perspectives and implications. J. Inform. Sci., 26: 381-397. DOI: 10.1177/016555150002600602

Widen-Wulff, G., 2000. Business information culture: A qualitative study of the information culture in the Finnish insurance industry. Abo Akademi University.

Wiley-Paton, S. and A. Malloy, 2004. Understanding Healthcare Professionals' Adoption and Use of IT'. Proceeding of the 10th Americas Conference on Information Systems, Aug. 6-8, New York, USA.

Williamson, L., N. Stoops and A. Heywood, 2001. Developing a district health information system in South Africa: A social process or technical solution? Stud. Health Technol. Inform., 84: 773-777. PMID: 11604842

Wilson, T.D., 1997. Information behaviour: An interdisciplinary perspective. Inf. Process. Manage., 33: 551-572. DOI: 10.1016/s0306-4573(97)00028-9

Yang, F., 2012. Exploring the information literacy of professionals in safety management. Safety Sci., 50: 294-299. DOI: 10.1016/j.ssci.2011.08.066

Young, D., 1984. What makes doctors use computers?: Discussion paper. J. Royal Soc. Med., 77: 663-667. 
Yu, P., H. Li and M.P. Gagnon, 2009. Health IT acceptance factors in long-term care facilities: A cross-sectional survey. Int. J. Med. Inform., 78: 219229. DOI: 10.1016/j.ijmedinf.2008.07.006

Yusof, M.M., J. Kuljis, A. Papazafeiropoulou and L.K. Stergioulas, 2008. An evaluation framework for health information systems: Human, Organization and Technology-fit factors (HOT-fit). Int. J. Med. Inform., 77: 386-398. DOI: 10.1016/j.ijmedinf.2007.08.011

Yusof, M.M., R.J. Paul and L.K. Stergioulas, 2006. Towards a framework for health information systems evaluation. Proceedings of the 39th Annual Hawaii International Conference on System Sciences, Jan. 04-07, IEEE Xplore Press, pp: 95a95a. DOI: 10.1109/hicss.2006.491
Zhang, J., 2005. Human-centered computing in health information systems. Part 1: Analysis and design. J. Biomed. Inform., 38: 1-3. DOI: 10.1016/j.jbi.2004.12.002

Zheng, Y., 2005. Information culture and development: Chinese experience of e-health. Proceedings of the 38th Annual Hawaii International Conference on System Sciences System Sciences, Jan. 03-06, IEEE Xplore Press, pp: 153a-153a. DOI: 10.1109/hicss.2005.315

Zhivan, N.A. and M.L. Diana, 2012. U.S. hospital efficiency and adoption of health information technology. Health Care Manage. Sci., 15: 37-47. DOI: $10.1007 / \mathrm{s} 10729-011-9179-2$ 